\title{
Iron: The Redox-active Center of Oxidative Stress in Alzheimer Disease
}

\author{
Rudy J. Castellani · Paula I. Moreira · Gang Liu • \\ Jon Dobson · George Perry · Mark A. Smith · \\ Xiongwei Zhu
}

Accepted: 17 April 2007/Published online: 17 May 2007

(C) Springer Science+Business Media, LLC 2007

\begin{abstract}
Although iron is essential in maintaining the function of the central nervous system, it is a potent source of reactive oxygen species. Excessive iron accumulation occurs in many neurodegenerative diseases including Alzheimer disease (AD), Parkinson's disease, and Creutzfeldt-Jakob disease, raising the possibility that oxidative stress is intimately involved in the neurodegenerative process. $\mathrm{AD}$ in particular is associated with accumulation of numerous markers of oxidative stress; moreover, oxidative stress has been shown to precede hallmark neuropathological lesions early in the disease process, and
\end{abstract}

Special issue dedicated to Dr. Moussa Youdim.

\section{R. J. Castellani}

Department of Pathology, University of Maryland,

Baltimore, MD, USA

\section{P. I. Moreira}

Center for Neuroscience and Cell Biology of Coimbra,

University of Coimbra, Coimbra, Portugal

G. Liu

Department of Radiology, University of Utah,

Salt Lake City, UT, USA

\section{J. Dobson}

Institute of Science and Technology in Medicine,

Keele University, Staffordshire, UK

G. Perry

College of Sciences, University of Texas at San Antonio,

San Antonio, TX, USA

G. Perry · M. A. Smith $(\bowtie) \cdot X$. Zhu

Department of Pathology, Case Western Reserve University,

2103 Cornell Road, Cleveland, OH 44106, USA

e-mail: mark.smith@case.edu such lesions, once present, further accumulate iron, among other markers of oxidative stress. In this review, we discuss the role of iron in the progression of $\mathrm{AD}$.

Keywords Alzheimer disease - Chelation ·

Neurodegeneration - Oxidative stress $\cdot$ Redox active iron

\section{Introduction}

As the incidence of Alzheimer disease (AD) continues to grow exponentially, progress in treating this disease continues to stagnate. Indeed, the leading effective therapy available today targets cholinergic deficits, i.e., the result of the disease process rather than the cause [1]. It is therefore not surprising that therapy provides some symptomatic relief only, and fails to alter the progression of the disease or outcome. This overall paucity of treatment options has provided impetus for potential treatment based on more fundamental pathogenic concepts (e.g., amyloid cascade hypothesis). Such approaches can be considered "lesioncentered" as they have as their foundation a specific hallmark lesion of $\mathrm{AD}$ (e.g., the senile plaque). The problem with the lesion-centered approach is that the hallmark lesions of $\mathrm{AD}$ also occur in "normal aging," and from the standpoint of the neuropathology of $\mathrm{AD}$, such lesions are more likely a consequence of the disease process rather than a cause [2]. Therefore, not surprisingly, progress in $\mathrm{AD}$ treatment based on lesion-centered hypotheses continues in a Brownian-like motion. A fundamental reorganization of the concepts related to etiology, pathogenesis, and treatment of $\mathrm{AD}$ seems warranted (e.g., [3]). In this review, we discuss the role of iron in $\mathrm{AD}$ pathogenesis as a potential therapeutic target. The relevance of iron in $\mathrm{AD}$ pathogenesis is suggested by data showing that: (1) 
iron is associated with oxidative stress and neurotoxicity; (2) iron accumulation and oxidative stress precede AD-associated lesions; and (3) iron is more readily treatable. We will outline the role of iron in cellular metabolism and neurodegenerative disease, and hopefully provide a stimulus to generate new ideas and new approaches for treating this devastating condition.

\section{Iron uptake, transport, and interaction with oxidative products}

Much like oxygen, iron is both an essential element for cellular metabolism, and a source of cytotoxicity when metabolism is dysfunctional. Indeed, excessive iron deposition is observed in the central nervous system (CNS) in a number of neurodegenerative diseases [4-6]. Iron uptake in the brain is tightly controlled by transferrin receptor in the endothelial cells and choroid plexus cells [7], or lactoferrin receptor on neurons $[8,9]$. For the export of iron from neurons or non-neuronal cells, a brain-specific ceruloplasmin is suggested to play a role $[10,11]$. The importance of ceruloplasmin in brain iron metabolism is highlighted by the extreme accumulations of iron in patients with hereditary aceruloplasminemia (R. J. Castellani, G. Perry, and M. A. Smith, unpublished observations).

The CNS uses its own transferrin whose expression is regulated by a CNS specific promoter [12, 13]. Regarding iron storage, ferritin binds and stores intracellular iron in most CNS cells, keeping it in a redox-inactive state [14]. In the pars compacta region of the substantia nigra, neuromelanin is known to play a part in iron storage [15]. To maintain iron homeostasis, iron regulatory protein-1 and -2 (IRP1 and IRP2) regulate the expression of ferritin and transferrin receptor post-transcriptionally through iron response element (IRE) [16]. Iron is involved in various cellular metabolisms, in particular, mitochondrial iron is incorporated into heme and cytochromes [17]. For the regulation of heme metabolism, heme oxygenase plays an important role in the CNS $[18,19]$.

During the reduction of molecular oxygen, mitochondria produce superoxide $\left(\mathrm{O}_{2}{ }^{--}\right)$. Enzymatic dismutation by superoxide dismutase (SOD) in turn yields hydrogen peroxide $\left(\mathrm{H}_{2} \mathrm{O}_{2}\right)$. Although $\mathrm{O}_{2}{ }^{--}$and $\mathrm{H}_{2} \mathrm{O}_{2}$ by themselves are relatively non-toxic, $\mathrm{H}_{2} \mathrm{O}_{2}$, which is freely permeable in tissues, may lead to the production of the highly toxic hydroxyl radical $(\mathrm{OH})$ through a metal ion-catalyzed Fenton reaction. This reaction is referred to as the superoxide-driven Fenton reaction or iron-catalyzed HaberWeiss reaction. Superoxide may also produce $\mathrm{H}_{2} \mathrm{O}_{2}$ nonenzymatically. In its normal metabolic state, superoxide favors the oxidation of $\mathrm{Fe}^{2+}$ to $\mathrm{Fe}^{3+}$. However, if the intracellular concentration of superoxide is elevated, the reaction favors the reduction of $\mathrm{Fe}^{3+}$ to $\mathrm{Fe}^{2+}$ and elaboration of hydroxyl radicals.

In light of the high levels of oxygen consumption in the CNS, the generation of a high level of reactive oxygen species (ROS) is expected, as well as anti-oxidant defenses commensurate with the free radical production. Under normal situations, oxidative balance is maintained and free radicals are detoxified. In disease, various modifications of macromolecules such as sugars, lipids, proteins, and nucleic acids, come into play, and it is now well established that neurodegenerative diseases are associated with oxidative imbalance and its sequelae. In the case of $\mathrm{AD}$, many lines of evidence now indicate that ROS induced by redoxactive metals including iron play a pivotal role in pathogenesis [20-29]. In the following sections, we will discuss the suggested mechanisms of iron in the neuropathology of AD.

\section{Iron deposition and senile plaques}

Iron accumulation in $\mathrm{AD}$ has been shown to be particularly abundant in brain regions vulnerable to $\mathrm{AD}$, including the hippocampal formation and association cerebral cortices [25]. At the microscopic level, it has been demonstrated to accumulate in senile plaques in $\mathrm{AD}$ [30]. Further, increases in iron accumulation and oxidative stress in $\mathrm{AD}$ brains are related with changes in the concentration of soluble and deposited amyloid- $\beta$ protein. Experimentally, such metabolic stresses including hypoglycemia, ischemia, and traumatic brain injury all augment amyloid- $\beta$ protein precursor formation and/or its mRNA [31-36]. Likewise, suppression of mitochondrial energy metabolism alters the processing of amyloid- $\beta$ protein precursor to produce amyloidogenic derivatives $[37,38]$ such that several studies have shown that oxidative stress increases the production of amyloid- $\beta$ [39-41], and that $\mathrm{H}_{2} \mathrm{O}_{2}$ affects increased intracellular [39, 42] and secreted amyloid- $\beta$ in neuronal cell lines [40]. On the other hand, amyloid- $\beta$ itself has been suggested to have an ability to generate ROS, driving a potential positive feedback loop whereby increased generation of ROS generates increased amyloid- $\beta$, and vice versa.

The three histidine residues of amyloid- $\beta$ at position 6 , 13 , and 14 and one tyrosine residue at position 10 , all located in the hydrophilic N-terminal part of the peptide $[43,44]$, behave as iron binding sites. The iron bound to these sites has been shown to generate $\mathrm{H}_{2} \mathrm{O}_{2}$ by the Fenton reaction [45-47]. Not only production of ROS but also binding of iron to these residues induces amyloid- $\beta$ aggregation. Substitution of the histidine residue significantly decreases the aggregation by $\mathrm{Fe}^{3+}$ [44]. Whether or not the aggregation of amyloid- $\beta$ and formation of senile plaques is important in neurotoxicity [23, 26, 48-50], it appears likely that extracellular iron is a major source of 
free radicals in the oxidatively damaged brain and that any deleterious effects of amyloid- $\beta$ are mediated by adventitiously bound iron [51]. Notably, the redox potential of iron is significantly attenuated by amyloid- $\beta$ suggesting a neuroprotective chelating role for amyloid- $\beta$ in disease pathogenesis [51, 52].

Besides the suggested direct involvement of iron, plaque formation also induces an activation of microglia or reactive astrocytes [53]. Activation of microglia and macrophages synthesize and secrete various cytokines such as interleukin (IL)-1, IL-6, and IL-8. Chronic production of these cytokines consequently causes activation of macrophages that produce large amounts of ROS [54]. Activated microglia also release iron from ferritin in a superoxide dependent fashion and result in lipid oxidation in vivo [55]. In fact, elevated levels of IL- 1 and IL-6 in AD brain have been reported [56]. Whether such microglial activation, like amyloid- $\beta$ activation [51], is mediated by iron is unclear.

\section{Iron in neurofibrillary tangles}

Neurofibrillary tangles (NFT) are another hallmark lesion of $\mathrm{AD}$ and, interestingly, are another site of iron accumulation. The presence of redox metals in NFT has been shown to induce oxidative stress via $\mathrm{H}_{2} \mathrm{O}_{2}$ [57]. Although NFT possibly act as a redox center, we previously demonstrated that neurons, which lack NFT also contain oxidative modifications [21], suggesting that oxidative stress precedes the formation of NFT.

Among the macromolecules modified by ROS, RNA is suggested as an early target of oxidative damage in $\mathrm{AD}$ brain [26]. Using 8-hydroxyguanosine (8OHG) as a marker of nucleic acid oxidation, oxidative damage can be found within the neuronal perikaryal cytoplasm. Moreover, 8OHG essentially disappears after treatment with RNase. Since $8 \mathrm{OHG}$ is formed by an attack of the hydroxyl radical, and cannot permeate through the plasma membrane, $8 \mathrm{OHG}$ must be produced within the cytoplasm in the vicinity of RNA. It is possible, therefore, that transition metals such as iron play a pivotal role in oxidation of RNA. In fact, studies show RNA oxidization is increased in AD brain [58] and subsequent protein translation is impaired [59].

Among the unanswered questions pertaining to the role of iron in neurodegenerative disease is the precise source of redox-active iron. Although mitochondria possess various iron containing functional molecules, such as heme, cytochrome, and aconitase, little 8OHG is accumulated. On the other hand in situ hybridization and ultrastructural observations reveal that mitochondrial abnormalities exist in AD brain and many abnormal mitochondria are targeted to lysosomes [60]. Since lysosomes also accumulate iron, mitochondrial turnover and lysosomal activity are a potential metabolic source of iron within damaged cells.

\section{Iron-containing compounds related to Alzheimer disease}

In spite of the importance of dysregulation of iron homeostasis in $\mathrm{AD}$ and other neurodegenerative diseases, relatively little is known about the resulting forms of iron, which accumulate in the brain. Recently, studies have begun to address this issue by using techniques such as synchrotron X-ray absorption spectroscopy (XAS), electron tomographic imaging, and superconducting quantum interference device (SQUID) magnetometry to characterize, locate and quantify specific iron compounds related to $\mathrm{AD}, \mathrm{PD}$, and other neurodegenerative diseases.

The development of XAS as a technique for analyzing and mapping iron and other metals related to tissue structures in avian brain tissue was first reported in 2005 [61]. Later that same year, Collingwood et al. [62, 63] demonstrated the application of this technique to AD tissue sections. This work provided the first map of iron distribution in $\mathrm{AD}$ tissue in which specific iron anomalies (areas of high iron concentration) were not only located but characterized with $5 \mu \mathrm{m}$ spatial resolution. It was clear from this work that the "normal" biological iron oxides, such as ferrihydrite and goethite-like hemosiderin, were not the only iron compounds responsible for these anomalies. Biogenic magnetite (a ferrimagnetic iron oxide $-\mathrm{Fe}_{3} \mathrm{O}_{4}$ - which contains both $\mathrm{Fe}^{2+}$ and $\mathrm{Fe}^{3+}$ ) was the primary component of many of the regions of high iron concentration.

Biogenic magnetite has been reported in human brain tissue from studies dating back to 1992 and is present as an iron biomineral in many species [64-66]. However, in a recent SQUID magnetometry study, Hautot et al. [67] reported elevated levels of biogenic magnetite in female AD subjects compared to both male and female controls. The significance of these findings is that magnetite provides a potential source of ferrous iron, which is available for oxidation and participation in Fenton chemistry (the oxidation product of magnetite, maghemite $-\gamma \mathrm{Fe}_{2} \mathrm{O}_{3}$, has also been found in $\mathrm{AD}$ tissue) and may potentiate free radical formation in $\mathrm{AD}$ tissue via triplet state stabilization [68-71].

These studies are beginning to highlight the importance of understanding the specific biochemical pathways associated with neurodegenerative diseases and the resulting iron compounds, which are formed. This is particularly important for the potential development of metal chelators as therapeutic agents [72, 73] and this information may also be exploited for non-invasive early detection of MRI 
based on the effects of magnetic iron compounds on proton relaxation rates as suggested several years ago $[68,74,75]$.

\section{Treatment potential}

To date, treatment of $\mathrm{AD}$ with chelating agents such as desferroxamine and clioquinol, a $\mathrm{Cu}^{2+}$ chelator, has been met with limited success [76, 77]. The reasons for this may be multifactorial. First, brain penetrant chelators are essential [78]. Second, as oxidative injury begins at a relatively early stage in disease, removal of iron by chelation therapy years later may simply be a case of too little too late. Early intervention is critical since the effects of oxidative stress are both cumulative and on-going. Moreover, iron is not the only source of free radicals within the brain. Other heavy metals (e.g., $\mathrm{Cu}, \mathrm{Hg}$, and $\mathrm{Pb}$ ), reactive nitrogen species, soluble mediators of inflammation, among other sources, may also play a role. In this respect, a multifaceted approach to treatment that targets early events, prior to the onset of neuropathology, makes more mechanistic sense. Targeting end-stage lesions likewise appears all the more naïve as understanding of $\mathrm{AD}$ and its relationship with the aging process continues to improve $[48,50,79,80]$.

\section{Conclusion}

There is no doubt that oxidative stress plays a pivotal role in pathophysiology of AD and in regards to ROS generation, iron would be a key molecule responsible for the formation of highly reactive hydroxyl radical. Both extracellular and intracellular events related to ROS generation have a great impact on the fate of neurons. Suggested by the successful reports of metal chelation therapy for improving neuronal function and cell viability, redox-active iron is an attractive target for treatment of neurodegenerative disease [81, 82]. Further investigation of iron will more clearly define the role of this redox-active element in the pathophysiology of AD.

Acknowledgments This study was supported by the National Institutes of Health, the Alzheimer's Association, and Philip Morris USA Inc., and Philip Morris International.

\section{References}

1. Marlatt MW, Webber KM, Moreira PI et al (2005) Therapeutic opportunities in Alzheimer disease: one for all or all for one? Curr Med Chem 12:1137-1147

2. Castellani RJ, Lee HG, Zhu X et al (2006) Neuropathology of Alzheimer disease: pathognomonic but not pathogenic. Acta Neuropathol (Berl) 111:503-509
3. Woods J, Snape M, Smith MA (2007) The cell cycle hypothesis of Alzheimer's disease: suggestions for drug development. Biochim Biophys Acta 1772:503-508

4. Rouault TA (2001) Systemic iron metabolism: a review and implications for brain iron metabolism. Pediatr Neurol 25:130 137

5. Rouault TA (2001) Iron on the brain. Nat Genet 28:299-300

6. Roy CN, Andrews NC (2001) Recent advances in disorders of iron metabolism: mutations, mechanisms and modifiers. Hum Mol Genet 10:2181-2186

7. Moos T (1996) Immunohistochemical localization of intraneuronal transferrin receptor immunoreactivity in the adult mouse central nervous system. J Comp Neurol 375:675-692

8. Kawamata T, Tooyama I, Yamada T et al (1993) Lactotransferrin immunocytochemistry in Alzheimer and normal human brain. Am J Pathol 142:1574-1585

9. Leveugle B, Spik G, Perl DP et al (1994) The iron-binding protein lactotransferrin is present in pathologic lesions in a variety of neurodegenerative disorders: a comparative immunohistochemical analysis. Brain Res 650:20-31

10. Patel BN, Dunn RJ, David S (2000) Alternative RNA splicing generates a glycosylphosphatidylinositol-anchored form of ceruloplasmin in mammalian brain. J Biol Chem 275:4305-4310

11. Klomp LW, Gitlin JD (1996) Expression of the ceruloplasmin gene in the human retina and brain: implications for a pathogenic model in aceruloplasminemia. Hum Mol Genet 5:1989-1996

12. Crowe A, Morgan EH (1992) Iron and transferrin uptake by brain and cerebrospinal fluid in the rat. Brain Res 592:8-16

13. Bowman BH, Jansen L, Yang F et al (1995) Discovery of a brain promoter from the human transferrin gene and its utilization for development of transgenic mice that express human apolipoprotein E alleles. Proc Natl Acad Sci USA 92:12115-12119

14. Lieu PT, Heiskala M, Peterson PA et al (2001) The roles of iron in health and disease. Mol Aspects Med 22:1-87

15. Double KL, Zecca L, Costi P et al (2000) Structural characteristics of human substantia nigra neuromelanin and synthetic dopamine melanins. J Neurochem 75:2583-2589

16. Hentze MW, Kuhn LC (1996) Molecular control of vertebrate iron metabolism: mRNA-based regulatory circuits operated by iron, nitric oxide, and oxidative stress. Proc Natl Acad Sci USA 93:8175-8182

17. Connor JR, Menzies SL, Burdo JR et al (2001) Iron and iron management proteins in neurobiology. Pediatr Neurol 25:118-129

18. Calabrese V, Scapagnini G, Ravagna A et al (2002) Regional distribution of heme oxygenase, HSP70, and glutathione in brain: relevance for endogenous oxidant/antioxidant balance and stress tolerance. J Neurosci Res 68:65-75

19. Maines MD (2000) The heme oxygenase system and its functions in the brain. Cell Mol Biol (Noisy-le-grand) 46:573-585

20. Marcus DL, Thomas C, Rodriguez C et al (1998) Increased peroxidation and reduced antioxidant enzyme activity in Alzheimer's disease. Exp Neurol 150:40-44

21. Sayre LM, Zelasko DA, Harris PL et al (1997) 4-Hydroxynonenal-derived advanced lipid peroxidation end products are increased in Alzheimer's disease. J Neurochem 68:2092-2097

22. Smith MA, Richey Harris PL, Sayre LM et al (1997) Widespread peroxynitrite-mediated damage in Alzheimer's disease. J Neurosci 17:2653-2657

23. Smith MA, Taneda S, Richey PL et al (1994) Advanced Maillard reaction end products are associated with Alzheimer disease pathology. Proc Natl Acad Sci USA 91:5710-5714

24. Smith MA, Perry G, Richey PL et al (1996) Oxidative damage in Alzheimer's. Nature 382:120-121

25. Smith MA, Harris PL, Sayre LM et al (1997) Iron accumulation in Alzheimer disease is a source of redox-generated free radicals. Proc Natl Acad Sci USA 94:9866-9868 
26. Nunomura A, Perry G, Pappolla MA et al (1999) RNA oxidation is a prominent feature of vulnerable neurons in Alzheimer's disease. J Neurosci 19:1959-1964

27. Zhou Y, Richardson JS, Mombourquette MJ et al (1995) Free radical formation in autopsy samples of Alzheimer and control cortex. Neurosci Lett 195:89-92

28. Martins RN, Harper CG, Stokes GB et al (1986) Increased cerebral glucose-6-phosphate dehydrogenase activity in Alzheimer's disease may reflect oxidative stress. J Neurochem 46:1042-1045

29. Pappolla MA, Omar RA, Kim KS et al (1992) Immunohistochemical evidence of oxidative [corrected] stress in Alzheimer's disease. Am J Pathol 140:621-628

30. Lovell MA, Robertson JD, Teesdale WJ et al (1998) Copper, iron and zinc in Alzheimer's disease senile plaques. J Neurol Sci 158:47-52

31. Hall ED, Oostveen JA, Dunn E et al (1995) Increased amyloid protein precursor and apolipoprotein $\mathrm{E}$ immunoreactivity in the selectively vulnerable hippocampus following transient forebrain ischemia in gerbils. Exp Neurol 135:17-27

32. Shi J, Perry G, Smith MA et al (2000) Vascular abnormalities: the insidious pathogenesis of Alzheimer's disease. Neurobiol Aging $21: 357-361$

33. Abe K, St George-Hyslop PH, Tanzi RE et al (1991) Induction of amyloid precursor protein mRNA after heat shock in cultured human lymphoblastoid cells. Neurosci Lett 125:169-171

34. Jendroska K, Poewe W, Daniel SE et al (1995) Ischemic stress induces deposition of amyloid beta immunoreactivity in human brain. Acta Neuropathol (Berl) 90:461-466

35. Murakami N, Yamaki T, Iwamoto Y et al (1998) Experimental brain injury induces expression of amyloid precursor protein, which may be related to neuronal loss in the hippocampus. J Neurotrauma 15:993-1003

36. Shi J, Xiang Y, Simpkins JW (1997) Hypoglycemia enhances the expression of mRNA encoding beta-amyloid precursor protein in rat primary cortical astroglial cells. Brain Res 772:247-251

37. Mattson MP, Pedersen WA (1998) Effects of amyloid precursor protein derivatives and oxidative stress on basal forebrain cholinergic systems in Alzheimer's disease. Int J Dev Neurosci $16: 737-753$

38. Gabuzda D, Busciglio J, Chen LB et al (1994) Inhibition of energy metabolism alters the processing of amyloid precursor protein and induces a potentially amyloidogenic derivative. J Biol Chem 269:13623-13628

39. Misonou H, Morishima-Kawashima M, Ihara Y (2000) Oxidative stress induces intracellular accumulation of amyloid beta-protein (Abeta) in human neuroblastoma cells. Biochemistry (Mosc) 39:6951-6959

40. Olivieri G, Hess C, Savaskan E et al (2001) Melatonin protects SHSY5Y neuroblastoma cells from cobalt-induced oxidative stress, neurotoxicity and increased beta-amyloid secretion. J Pineal Res 31:320-325

41. Frederikse PH, Garland D, Zigler JS Jr et al (1996) Oxidative stress increases production of beta-amyloid precursor protein and beta-amyloid (Abeta) in mammalian lenses, and Abeta has toxic effects on lens epithelial cells. J Biol Chem 271:10169-10174

42. Paola D, Domenicotti C, Nitti M et al (2000) Oxidative stress induces increase in intracellular amyloid beta-protein production and selective activation of betaI and betaII PKCs in NT2 cells. Biochem Biophys Res Commun 268:642-646

43. Atwood CS, Scarpa RC, Huang X et al (2000) Characterization of copper interactions with alzheimer amyloid beta peptides: identification of an attomolar-affinity copper binding site on amyloid beta1-42. J Neurochem 75:1219-1233

44. Atwood CS, Moir RD, Huang X et al (1998) Dramatic aggregation of Alzheimer abeta by $\mathrm{Cu}(\mathrm{II})$ is induced by conditions representing physiological acidosis. J Biol Chem 273:1281712826

45. Curtain CC, Ali F, Volitakis I et al (2001) Alzheimer's disease amyloid-beta binds copper and zinc to generate an allosterically ordered membrane-penetrating structure containing superoxide dismutase-like subunits. J Biol Chem 276:20466-20473

46. Huang X, Atwood CS, Hartshorn MA et al (1999) The A beta peptide of Alzheimer's disease directly produces hydrogen peroxide through metal ion reduction. Biochemistry (Mosc) 38:7609-7616

47. Dikalov SI, Vitek MP, Maples KR et al (1999) Amyloid beta peptides do not form peptide-derived free radicals spontaneously, but can enhance metal-catalyzed oxidation of hydroxylamines to nitroxides. J Biol Chem 274:9392-9399

48. Perry G, Nunomura A, Raina AK et al (2000) Amyloid-beta junkies. Lancet 355:757

49. Smith MA, Joseph JA, Perry G (2000) Arson. Tracking the culprit in Alzheimer's disease. Ann NY Acad Sci 924:35-38

50. Joseph J, Shukitt-Hale B, Denisova NA et al (2001) Copernicus revisited: amyloid beta in Alzheimer's disease. Neurobiol Aging 22:131-146

51. Rottkamp CA, Raina AK, Zhu X et al (2001) Redox-active iron mediates amyloid-beta toxicity. Free Radic Biol Med 30:447-450

52. Rottkamp CA, Atwood CS, Joseph JA et al (2002) The state versus amyloid-beta: the trial of the most wanted criminal in Alzheimer disease. Peptides 23:1333-1341

53. Cullen KM (1997) Perivascular astrocytes within Alzheimer's disease plaques. Neuroreport 8:1961-1966

54. Dunn CJ (1991) Cytokines as mediators of chronic inflammatory disease. In: Kimball ES (ed) Cytokines and inflammation. CRC, Boca Raton, FL, pp 1-33

55. Yoshida T, Tanaka M, Sotomatsu A et al (1998) Activated microglia cause iron-dependent lipid peroxidation in the presence of ferritin. Neuroreport 9:1929-1933

56. Cadman ED, Witte DG, Lee CM (1994) Regulation of the release of interleukin-6 from human astrocytoma cells. J Neurochem 63:980-987

57. Sayre LM, Perry G, Harris PL et al (2000) In situ oxidative catalysis by neurofibrillary tangles and senile plaques in Alzheimer's disease: a central role for bound transition metals. J Neurochem 74:270-279

58. Shan X, Tashiro H, Lin CL (2003) The identification and characterization of oxidized RNAs in Alzheimer's disease. J Neurosci 23:4913-4921

59. Honda K, Smith MA, Zhu X et al (2005) Ribosomal RNA in Alzheimer disease is oxidized by bound redox-active iron. J Biol Chem 280:20978-20986

60. Hirai K, Aliev G, Nunomura A et al (2001) Mitochondrial abnormalities in Alzheimer's disease. J Neurosci 21:3017-3023

61. Mikhaylova A, Davidson M, Toastmann H et al (2005) Detection, identification and mapping of iron anomalies in brain tissue using X-ray absorption spectroscopy. J R Soc Interface/R Soc 2:33-37

62. Collingwood JF, Mikhaylova A, Davidson M et al (2005) In situ characterization and mapping of iron compounds in Alzheimer's disease tissue. J Alzheimers Dis 7:267-272

63. Collingwood JF, Mikhaylova A, Davidson MR et al (2005) Highresolution $\mathrm{x}$-ray absorption spectroscopy studies of metal compounds in neurodegenerative brain tissue. J Phys: Conf Ser 17:54-60

64. Dobson J, Grassi P (1996) Magnetic properties of human hippocampal tissue-evaluation of artefact and contamination sources. Brain Res Bull 39:255-259

65. Schultheiss-Grassi PP, Wessiken R, Dobson J (1999) TEM investigations of biogenic magnetite extracted from the human hippocampus. Biochim Biophys Acta 1426:212-216 
66. Kirschvink JL, Kobayashi-Kirschvink A, Woodford BJ (1992) Magnetite biomineralization in the human brain. Proc Natl Acad Sci USA 89:7683-7687

67. Hautot D, Pankhurst QA, Khan N et al (2003) Preliminary evaluation of nanoscale biogenic magnetite in Alzheimer's disease brain tissue. Proceedings 270(Suppl 1):S62-S64

68. Dobson J (2001) Nanoscale biogenic iron oxides and neurodegenerative disease. FEBS Lett 496:1-5

69. Dobson J (2004) Magnetic iron compounds in neurological disorders. Ann NY Acad Sci 1012:183-192

70. Timmel CR, Till U, Brocklehurst B et al (1998) Effects of weak magnetic fields on free radical recombination reactions. Mol Phys 95:71-89

71. Scaiano JC, Monahan S, Renaud J (1997) Dramatic effect of magnetite particles on the dynamics of photogenerated free radicals. Photochem Photobiol 65:759-762

72. Bush AI (2002) Metal complexing agents as therapies for Alzheimer's disease. Neurobiol Aging 23:1031-1038

73. Shachar DB, Kahana N, Kampel V et al (2004) Neuroprotection by a novel brain permeable iron chelator, VK-28, against 6hydroxydopamine lession in rats. Neuropharmacology 46:254-263

74. Bartzokis G, Tishler TA, Lu PH et al (2007) Brain ferritin iron may influence age- and gender-related risks of neurodegeneration. Neurobiol Aging 28:414-423

75. Jack CR Jr, Wengenack TM, Reyes DA et al (2005) In vivo magnetic resonance microimaging of individual amyloid plaques in Alzheimer's transgenic mice. J Neurosci 25:10041-10048
76. Ritchie CW, Bush AI, Mackinnon A et al (2003) Metal-protein attenuation with iodochlorhydroxyquin (clioquinol) targeting Abeta amyloid deposition and toxicity in Alzheimer disease: a pilot phase 2 clinical trial. Arch Neurol 60:1685-1691

77. McLachlan DR, Kruck TP, Lukiw WJ et al (1991) Would decreased aluminum ingestion reduce the incidence of Alzheimer's disease? CMAJ 145:793-804

78. Liu G, Garrett MR, Men P et al (2005) Nanoparticle and other metal chelation therapeutics in Alzheimer disease. Biochim Biophys Acta 1741:246-252

79. Smith MA, Atwood CS, Joseph JA et al (2002) Predicting the failure of amyloid-beta vaccine. Lancet 359:1864-1865

80. Lee HG, Casadesus G, Zhu X et al (2004) Challenging the amyloid cascade hypothesis: senile plaques and amyloid-beta as protective adaptations to Alzheimer disease. Ann NY Acad Sci 1019:1-4

81. Kaur D, Yantiri F, Rajagopalan S et al (2003) Genetic or pharmacological iron chelation prevents MPTP-induced neurotoxicity in vivo: a novel therapy for Parkinson's disease. Neuron 37: 899-909

82. Cherny RA, Atwood CS, Xilinas ME et al (2001) Treatment with a copper-zinc chelator markedly and rapidly inhibits betaamyloid accumulation in Alzheimer's disease transgenic mice. Neuron 30:665-676 